\title{
The Choice of Health Care Providers among Old Order Amish in a Pennsylvania Valley
}

\author{
Gretchen Schafft \\ Public Anthropologist in Residence \\ American University \\ gschafft@verizon.net
}

\begin{abstract}
The Amish offer an interesting mix of conventional and complementary choices regarding health care and health care professionals. Based on the author's experiences in an Amish community located in a valley of central Pennsylvania, these culturally based advantages and disadvantages in choices are discussed. The article concludes with a set of recommendations for developing improved and culturally appropriate practices for the Amish and their interactions with health care providers.
\end{abstract}

Submitted March 3, 2020; accepted June 14, 2020; published September 18, 2020

https://doi.org/10.18061/jpac.v1i1.7804

Keywords: health care providers, complementary and alternative medicine (CAM), Amish dentist, psychological care, chiropractors, culturally appropriate health care

\section{Introduction}

Emma, eleven years old, came to the gate with two new dogs, both friendly, healthy, mediumsized, of indeterminate origin, and not barking. If I had come when no one was home, they would have made a lot of noise: good watch dogs.

Emma seemed her usual, cheery self and greeted me warmly. Her mother, Melissa, appeared a minute later, and the three of us hopped into my car to go to the farm market for flowers to plant in my front yard.

As soon as Emma was occupied elsewhere, Melissa told me that Emma was not feeling too well. She had recently had seven teeth pulled by the "Amish dentist." I tried to suppress my alarm, and asked, "Were they baby teeth or permanent teeth?" Melissa said they were permanent teeth, all on the lower jaw. I asked why this procedure was necessary and what would be the next step in giving Emma the care she would need. Melissa appeared unflappable and told me that when they could afford it, they would get Emma false teeth.

There was no opportunity to ask the questions that immediately came to my mind: Did the dentist take x-rays? Why did he feel it was necessary for such a major extraction? How did he define the dental condition of Emma's mouth? What steps would be followed to assure that she could eat properly? How would her family meet her nutritional needs? ${ }^{1}$

\footnotetext{
${ }^{1}$ See Heima et al., "Oral Health and Medical Conditions." This study reviewed the dental records of 216 Amish children in 2011 and found that almost 28 percent of them, ages 3 to 17, had never seen a dentist and had an average number of 6.8 untreated decayed teeth. Because 87 percent of their parents rated their
} 
When our day together was over, I called my own dentist and explained the situation. He said that Emma should, in his professional opinion, see a pediatric dentist and get a full set of x-rays showing if there were any teeth that eventually would be coming in. A dentist should assess the extent to which the rest of her teeth were impaired and which of her natural teeth might be useful in affixing any prosthesis. He told me that within two years her body would close the sockets where her missing teeth had been, and it would be increasingly difficult for her to use any functioning dentures in the place of those teeth no longer there.

I had been in the midst of collecting information on a range of emic-described "health care providers" and their functions as defined by members of this Amish community. ${ }^{2}$ After hearing about Emma's experience and Melisa's explanation, my research focus shifted. I began to look at why alternative health care providers are used in this community, how these choices are determined, and how their selection affects the lives of adults and children within the community of this particular group of Old Order Amish. ${ }^{3}$

The observations in this paper are based on my field notes from five years of ethnographic inquiry in a small, rural community in central Pennsylvania where I live part-time and serve as a volunteer "driver" for one extended family. I have also noted interactions within the larger community among various Amish groups and the English. Approximately 500 hours of participant observation were the primary source of information. (No formal interviews were conducted.) The bishop of this Gemeinde, or congregation, of Old Order Amish participants made it clear to me in an interview that he wished no formal investigation be done, and wanted his congregants to keep the traditional distance from the English (a term used for the non-Amish), a label with which I am identified.

I did not want to cause discord, so I made no attempt to direct predetermined questions to the women and children with whom I was in close contact. Despite their understanding this directive from the bishop and discussing it with me, my Amish friends did not change their habits of meeting me regularly at my house or theirs, albeit informally. The women enjoyed our regular excursions on shopping trips, short and long visits to clinics and doctors' offices, and rare but stimulating meals and conversations in restaurants at my invitation. Occasionally, we shared a dinner with multiple generations of the extended family at several different houses. I am grateful and appreciative for the trust that my Amish neighbors extended to me and their willingness to cross rather formidable barriers to do this, and I am, in turn, careful to mask their individual and community identities. ${ }^{4}$

children's oral health as good or very good, the researchers concluded that there was "a lack of awareness among Amish parents with regard to their children's oral health" (p. e338).

${ }^{2}$ The term emic refers to ethnographic description from a "native" point of view rather than from an outsider's viewpoint. See the Oxford English Dictionary for a more complete definition.

${ }^{3}$ Crawford, Manuel, and Wood, "Pharmacists' Considerations."

${ }^{4}$ The author is aware that treating the cultural divide in this rural community between Amish and English leads to an unwelcome stereotyping of the two populations, when, in fact, neither is a homogeneous entity. This is a heuristic device, which the reader is urged to recognize. 


\section{The Concept of "Health Care Provider" in the Community: General Observations}

As with many aspects of verbal communication between the English and the Amish, words and sentences may sound the same to both groups, but mean different things. A phrase like "health care provider" can conjure up various jobs. For example, educated English people may consider the knowledge of an herbalist to be useful to their well-being, but rarely would she be defined as a "health care provider." The Amish would assign the titles "doctor" and "dentist" to people acting to diagnose and treat various maladies without regard to training or certification. ${ }^{5}$

The English in this community use allopathic practitioners, trained in medical schools, for most of their medical needs; however, some English claim that they avoid allopathic practitioners as much as they can, using them only for long-standing, debilitating illnesses or where a crisis appears to be involved. For less serious ailments, many English use complementary and alternative medicine (CAM), such as chiropractors, midwives, herbalists, acupuncturists, and massage therapists. 6

Amish make use of folk dispensaries operated by those perceived to have accumulated Amish wisdom about remedies, but their products are largely commercially produced. In this community, this type of store is operated out of a farm, and its location is not well known to English residents. Such stores are not referred to as "drug stores" or "pharmacies," but as the store belonging to the named proprietor or the store on a named road (e.g., "Alice's store" or "the store on Red Bird Road").

Some English community members derogatorily refer to other English who regularly seek alternative sources of health care as "anti-vaccine" people. However, both the English and Amish communities seem tolerant of many different approaches to care and health promotion, and generally people do not judge others for their choices. At least one study has shown that both communities are familiar with and use CAM care extensively. ${ }^{7}$

The Amish refer to Amish practitioners with titles that they assign without requiring the assumed credentials. For instance, the Amish "doctor" did not go to high school, college, or medical school. It appears that the English would be far less likely to use an Amish "dentist" who has no identifiable training in a school of dentistry and virtually no modern equipment. In fact, due to the prohibition on the use of electricity, drilling of teeth would be difficult if not impossible. Xray machines are also not found in these offices. Waiting until the tooth needs to be extracted places the Amish "dentist" in a positive legal position. He is just being neighborly by pulling a

\footnotetext{
${ }^{5}$ Adams and Leverland, "Effects of Religious Beliefs"; Kristofferson et al., "Prevalence, and Health and Sociodemographic Associations." It appears that Amish who identify with these descriptors are careful of the legalities of "practicing without a license." They may have a well-understood fee for service, but do not charge that fee openly. Instead, they ask for a "donation." I have not been able to establish any oversight by the Pennsylvania Dental Association of these practices. In conversation, Dr. D. Holmes Morton told me of one Amish dentist being brought to court and given a $\$ 10,000$ fine which he paid and then went back to practicing "dentistry."

${ }^{6}$ de Jonge et al., "Complementary and Alternative Medicine Contacts."

${ }^{7}$ Reiter et al., "Complementary and Alternative Medicine Use."
} 
"bad tooth" as opposed to making a decision to actually treat a dental condition. However, some "dentists" inject pain medication, apparently overlooked by the health departments involved. Similarly, no English people use the term "medical technician" to describe those who provide extensive care in the Amish community without having recognized licenses to practice medicine. English neighbors appear to largely ignore or not be aware of dental treatments undertaken by Amish practitioners, and the Amish are careful not to state the names and addresses of the practitioners, or details about their services.

Economic considerations figure prominently in decision-making regarding hospital care. Both the Amish and the English may use hospitals, hospice care, and inpatient clinics when faced with very serious illness or impending death, but the English will more readily than the Amish see this kind of care as a normal progression of medical treatment from primary to secondary to tertiary care. ${ }^{8}$ The Amish keep unavoidable stays in a hospital as short as possible and use CAM as long as they can. Hospitals are inconvenient and expensive. Even if the community funds help to pay the expenses, members of the Gemeinde may gossip about the expenses, the need for the treatment, and the burden these payments place on the available church funds. Usually inpatient treatment requires traveling on major roads for more than the 20 miles; in other words, inappropriate for horse-drawn transportation. Thus, the cost of hiring a van ride must be factored in, and if family members wish to visit the patient while in inpatient care, that cost will be multiplied. Hospital personnel often appear culturally distant from their Amish patients and often uninformed. Hospice care provided in the home, on the other hand, is a service welcomed by most Amish in my study. Having a nurse visit the patient in his or her own bedroom, give palliative treatment, and provide care close to the natural choices of the family is culturally compatible.

\section{Peer Consultation and Treatment among the Amish}

D. Holmes Morton, MD, a renowned pediatrician and geneticist, has spoken of training mothers to do peer counseling in the case of infants born with terminal genetic conditions for which there is no chance of survival. ${ }^{9}$ Mothers of such children in at least one community were trained in the care of their own children and were able to keep them at home, virtually from birth to death, providing them with love and tender care in the midst of the family. Other children in the family experienced the eventual death of the infant with an understanding that they had helped to care for their sibling. Hospital bills were modest, and the infant was not subjected to tests and other procedures within the sterile hospital environment. With the help of Dr. Morton or his staff, to the extent possible, each mother experiencing this difficult time taught another mother the caregiving techniques in an effort to provide the most humane experience possible for a very short life.

\footnotetext{
${ }^{8}$ Rohr et al., "Utilization of Health Care Resources."

${ }^{9}$ D. Holmes Morton, "Plain People, Genomics and the Art of Translational Medicine" (plenary address, "Continuity and Change: 50 Years of Amish Society" conference, Young Center for Anabaptist and Pietist Studies, Elizabethtown College, Elizabethtown, PA, June 11, 2016).
} 
Peer treatment can also involve children in other ways. From a very early age, children are often enlisted in the care of their siblings' minor illnesses or accidents. I observed a child of six as he was instructed to get the medical kit out from under a bed when his sister came in the house crying with a cut on her bare foot. He efficiently did as his mother told him. As she wiped off the wound, he opened a suitcase and took out salve and bandages. He applied the salve and wrapped the foot carefully, tying the ends of the bandage so it would not slip off. He neatly replaced the materials and put the suitcase back where he had found it. The mother gave him a warm smile, but did not praise him for his efforts. It was a task that was understood as necessary and helpful by both of them.

What was not understood, in this case, was the necessity of thoroughly washing the wound. Neither his mother nor the boy thought to do so, and the bandage was placed over a foot that had been in the barn and the yard without a shoe to protect it. The little girl no longer cried and went back outside barefoot. In subsequent visits, I did not see any lasting result of the injury, while the self-esteem of the six-year-old boy was reinforced as he carried out an important task for his very tired mother and showed himself to be a valuable family member. English children may rarely have such an opportunity, or take such a risk, in service of another.

A different form of more organized peer health care provision is found in the group of men in the community who form a kind of health care cadre. They attend to many kinds of illnesses and accidents in their own special way. One example occurred last summer. I was visiting Sarah, an Amish friend, on her front porch when a young girl came riding up on her scooter. She asked if Sarah had any red beets. ${ }^{10}$ Sarah asked if she needed the beets for her father and, by the way, how was he doing? Having been assured that he was doing better, Sarah said she had no beets left after market day, but knew of another neighbor who still had some in the field that had not yet been harvested. I volunteered to drive the girl to the neighbor's house, which was some distance away, but she hurried away on her scooter shouting "no thanks" over her shoulder.

When the girl was out of sight, Sarah told me that the man had cut off his toes and the front part of his foot by dropping a heavy piece of metal on it. He was rushed to the hospital, where he stayed for several days, was given antibiotics, and had the foot cleaned of bone fragments and sewn up. He then went home, and the Amish medical team moved into his house. They stayed with him day and night, changing the bandages, using a special salve and red beets to cover the wound before rewrapping it. I saw one of the team members at a farmers' market a week later. I asked how Mr. Schmidt's foot was doing, and he said, "Well, he'll never run again, but he should be able to work in his field in a few weeks." What elements of the care given by the team were effective? Was it the psychological support of the injured man's friends? Was it the constant cleaning and changing of bandages? Was it some combination of the two that assured the patient

\footnotetext{
${ }^{10}$ Flurry et al., "Salve and Burdock."
} 
that he remained part of the community even if he was impaired? Were beets and salve actually good medicine or was the initial treatment in the hospital with antibiotics totally effective? ${ }^{11}$

\section{Allopathic Health Care Options and the Amish}

Certainly, as has been discussed, a barrier the Amish face in using medical doctors and hospitals is cost. The Amish do not generally participate in public or private insurance programs, but depend on a community fund to which they contribute according to their means to pay medical bills that they cannot pay on their own. My contacts report that most Amish in their church community are laboring at eight to ten dollars an hour if they work outside their own farms or businesses. There is little money reserved for medical emergencies or chronic care. Farm employment is generally a low-profit venture. A committee of Amish men are selected to regularly negotiate with doctors and hospitals for reduced rates, and in this Amish-rich area, they seem always successful in gaining some consideration. ${ }^{12}$ They use the hospital sparingly, and very often leave the institution behind to continue care through CAM.

In the community under discussion here, the Amish are often described as "living in poverty," which seems a misguided description of their lives. ${ }^{13}$ True, in this settlement, they buy very little and prefer to shop in stores run by Amish or Mennonites that specialize in damaged canned goods or overstocks. Their purchases are generally for materials from which to produce their own necessities, such as sewing supplies, parts for their simple machines, or batteries. Their cash purchases are modest and they do not give gifts for holidays. They have no autos, gas-driven machinery, or decorative additions to their homes. The cleanliness and beauty they produce in their surroundings are works of their own labor; thus, their major expenses are seed and fertilizer, construction materials, shoes, and paying drivers. Their "poverty" does not mean they are hungry or homeless or poorly clothed, as it might in a low-income English community.

The Amish depend on horses and nonmotorized vehicles for transportation. A trip to an urban area where hospitals and many doctors are located takes more hours than horses can endure. The cost of a "van ride" can be difficult if the facility is far away. Finding a local solution is favored, which may mean an Amish midwife, dentist, chiropractor, massage therapist, or herbalist. Sometimes, Amish households will travel to Mexico by train for operations that cannot be avoided and are prohibitively expensive closer to home, such as orthopedic surgery. Again, the desire to control costs is crucial. Even when factoring in the train tickets and associated travel costs, it may be considerably cheaper to have a procedure done in Mexico.

\footnotetext{
${ }^{11}$ The peer medical team requested that their patient be released from the hospital before the medical staff wanted him to leave. The request was made to avoid hospital infection, to reduce the cost of the hospitalization, and to provide their favored care in a home setting.

${ }^{12}$ Kraybill, The Amish and the State, 9.

${ }^{13}$ Hurst and McConnell, Amish Paradox, 178, 192, 227, note the perception that the Amish in the community they study, in Ohio, live in poverty.
} 
It is clear that the Amish in my community prefer to be taken care of by someone who "speaks like us." This does not refer to the Pennsylvania Dutch language, but to an understanding of the religious and cultural values, beliefs, and traditions of the group. ${ }^{14}$ Going to the hospital can be very frightening for anyone, but for an Amish patient it involves more difficulties with technology and assumptions that go along with modern care.

On the other hand, dealing with hospital doctors can enrage Amish patients and families. Two fathers whose children were hospitalized for very serious procedures talked about their reactions to doctors who did not explain what they were doing for the children. "I shouted at him that I was not stupid. I wanted to know. He only said that he was seeing what the problem entailed and could not tell me right now," one said. The other man said, "I balled up my fists. I was going to hit the doctor and he knew it. I really told him off!" In reality, having known these men for some time, I doubted if either had raised his voice or threatened the doctors, but the narrative certainly expressed their frustration and what they felt like doing.

Despite limited formal education, many Amish know the terms for advanced technology like MRI and PET scan. One mother told me that she waited all day in the hospital for her child to have such a procedure and finally went to the nurses' desk to demand that the test be given. Another told me that a neighbor's child had died in the hospital and was returned "all cut in pieces." The hospital had not understood or valued her desire to take her terminally ill child home to spend his last days. "We would rather have our children with us when they die than in the hospital where no one knows them" is a common sentiment.

Similarly, Amish parents insist that children with profound physical and developmental disabilities should remain in the family home and not be placed in institutional care settings. These children are referred to as "God's special children" by the community and are traditionally treated gently and with great care. Most Amish believe that God has provided the parents of such children, not with a burden, but with an opportunity for spiritual growth in patience, self-sacrifice, and heightened faith. As one family struggles with caregiving added to their daily tasks, other members of the community will help in many different ways: baby-sitting, bringing meals, helping with house or garden work, or providing actual health care.

\section{Choosing Psychological Care and Community Support}

The mental health needs of the Amish are varied and sometimes serious. Some conditions, such as bipolar disorder, may be rooted in genetics. In other cases, it is possible that there are socioeconomic-cultural stresses that are distinctive to the Amish social environment that may produce anxiety or depression. Most mental health cases are handled within the community, but some culturally specific facilities exist for inpatient care for Amish men, women, and adolescents with a mental illness. ${ }^{15}$ One family recognized that a young married man with a wife and two children

\footnotetext{
${ }^{14}$ Cates, Serving the Amish, 191-96.

${ }^{15}$ The Green Pasture residence and the associated Plain Communities Outpatient Clinic in Mt. Gretna, Pennsylvania, is one center for Amish and other Plain Anabaptist patients needing psychological care.
} 
was behaving strangely in the eyes of the extended family, and they decided that after many attempts to accommodate him, he needed the Amish inpatient care that was available to him. He resisted going away until his brother-in-law, who had a job and a family of his own, told him, "I think I have some mental problems, too. I could use some help. Why don't we go together, and we'll both are better for it?" This was not a trick to get the patient into care, but a sincere offer supported by the helper's hard-working wife and mother of six, who knew that others in the community would certainly help her in her husband's absence.

In my observation of this community, those struggling with mental illnesses are likely to find the community gathering around them rather than avoiding them. There seems to be little stigma and a great deal of support from family and the community. Underlying these attitudes is the belief that God has planned the life circumstances in which we find ourselves and we cope accordingly. This fatalistic view increases motivation to care for the infirm, but also sometimes stands in the way of seeking help, acting proactively to avoid accidents, and providing adequate supervision of children and handicapped adults.

In the case previously described, the patient was provided an inpatient stay in an Amish facility and then released to his family and community while continuing to take a psychotropic drug prescribed by the mental health clinic. A mental health fellowship group was formed from members of the Gemeinde, and this group of five men met regularly with the patient in his home to discuss his concerns. He told the group about his anxieties and his ideations. They responded with empathy and a revised view of the patient's perceptions. They placed their advice to him in terms of what God and the community wanted from him. As the patient improved, members of the group took him along to their work sites and reminded him, when he "got off track," that the community and God wanted him to conform to expectations for good behavior. They were consistently supportive and reported that, in a few months, he had led a parent-school meeting very effectively. They were all very happy for his improvement, of which they felt a part.

\section{Pluses and Minuses of CAM Care among the Old Order Amish}

Because there is very little or no science training in the Amish school system, it is hardly surprising that folk traditions and beliefs are highly influential in the Old Order Amish communities.

Language alone is one determining factor. While most of the people practicing CAM are not speakers of Pennsylvania Dutch, they are used to talking to Amish people and listening carefully to their complaints. The Amish occasionally say, "I like her because she speaks like us," whereby they conflate listening with speaking. The reduction of social distance is based on the lack of medical jargon, understanding of Amish fatalism, respect for the client, and appreciation of the Plain people of the community.

Located on the campus of Philhaven, a conventional behavioral health care center, Green Pasture provides patients with a culturally sensitive in-patient facility with Amish house parents and Pennsylvania Dutchspeaking therapists, as well as the conventional psychiatric and psychological professional resources of Philhaven. Kraybill, Johnson-Weiner, and Nolt, The Amish, 348-49; and Cates, Serving the Amish, 192. 
Descriptions of medical conditions by doctors and staff within a hospital or clinic setting of allopathic medicine may be far beyond what a person with no basic scientific understanding can comprehend. Yet, when Amish perceive that they are being treated as ignorant and incapable of grasping their loved one's condition, they are insulted, and perhaps intimidated or angry.

On the other hand, explaining an illness from a CAM perspective is closer to a natural explanation of forces they may understand. The fact that the chiropractor uses body-to-body contact is comforting to the Amish. News of a particularly competent and approachable chiropractor spreads through the community, and vanloads of patients and their families will travel long distances for a treatment with a well-known practitioner. One family reported that a child of seven was aggressive and restless, so they took him to Nebraska for treatment by a chiropractor. They were satisfied with the results, and while the child remained active in play, he was well within the family norms of behavior. The family would not divulge the nature of the treatment to me.

There is no indication that the chiropractor has training in the number of genetic conditions found in the community. Their in-service training program does not seem to have targeted the Amish as a special case for consideration. There certainly is the potential for missed or false diagnoses when a family engages only with chiropractic medicine, but such adherence carries none of the suspicion that allopathic medicine carries.

The extensive use of chiropractors extends to infants. I was driving one family to an allopathic clinic so that a doctor could examine a baby who was about eight months old and showing signs of "failure to thrive." On the way, the baby's mother asked if we had time to drop by the chiropractor's office for an "adjustment." I asked her who needed it. She replied it was for the baby. In her experience, a "manipulation" by the chiropractor was a more certain remedy than anything the clinic could supply.

Doctor-patient consultation is not usually in depth. One group of Amish women arranged transportation to a doctor trained in India because he spent time with the mothers of his patients and explained clearly his diagnoses and treatment options. He was much more open to folk remedies than other doctors they had tried. His prices were modest and he stocked common medicines in his office so that a trip to the pharmacy was not usually necessary. When he moved his practice 30 miles away, the women of the area regretted their loss.

The greatest deficit in CAM with this population is the lack of science-backed care and the lost opportunity for educating the community about vectors of disease, genetic implications of common disabilities and maladies, and simple rules of nutrition, safety, and sanitation. Using instead nonfactual discussions of morbidity encourages people to continue behaviors that are not optimal for the good health of children or adults. To the extent that muscle aches and pains so common in hard-working manual laborers can be mitigated, the services of CAM providers are welcome. To the extent that their practices do not contradict the fatalism of the Amish religious beliefs, they are welcome into their clients' lives. 


\section{Conclusions and Reflections}

Culturally appropriate health care is valued by those who make use of it and by modern practitioners who believe that the patient and the provider share in maintaining and improving the individual's well-being. Many CAM and allopathic practitioners have a natural or learned ability to "speak like" the Amish and be well understood by their patients. This ability must be acknowledged and appreciated. However, the medical outcomes must match the empathy that these practitioners express.

Examining the modes of health care delivery to the Amish and the efficacy of their outcomes is made more difficult by the very privacy, and even secrecy, with which the Old Order Amish guard their practices. Most of the people with whom I spoke were well aware of the illegality of unlicensed practitioners and never willingly gave their names or spoke of where the services were provided. Although almost no actions have been taken in this community against unlicensed people acting as dentists and doctors, there is a general understanding that they are practicing outside regulations and, possibly, the law. Therefore, the extent of their presence in the lives of the community is impossible to gauge except by observation.

In fact, rates of morbidity, and possibly mortality, are uncertain in certain Amish settlements. In some very conservative affiliations, particularly in more remote geographic areas, not all births and deaths may be registered. In the valley community I know best, I can think of many instances in which death may not be a part of the public record. Living "under the radar" is a major value among the Amish, and the passing into and out of life may not be invariably reported to public health authorities. Who is recording morbidity rates if the patient is not seen by a licensed medical doctor? Do those reporting a death necessarily know how to attribute the death? In other words, gathering useful statistics on health, wellness, and illness is not a straightforward task. Perhaps the qualitative methods of the anthropologist are more appropriate for mortality and morbidity studies of the Amish since careful observation and respect for the power of group culture are nonthreatening methods that protect the people who are subjects of the inquiry.

Myths about the Amish abound and are propagated even by those who know them quite well. It is easy to stereotype the different groups of Amish, although there is great variability, not only among different affiliations, such as the Nebraska Amish, the Lancaster Amish, or the Swartzentrubers. The variability goes to the church district, or Gemeinde, level, which is made up of 30 to 50 families living in close proximity. Depending on the affiliation, individual church districts may have noticeable leeway in forming or relaxing church discipline and, thus, their way of life. ${ }^{16}$

The role of state regulators in seeing that cultural norms do not dilute health care equality is critical to recognition and enforcement of medical standards. Regulatory agents should check communities for those posing as medical doctors or dentists and educate the populace on the value of training and education in choosing care for their families. Children should not have their teeth extracted because they have been denied dental care and good nutritional counseling in their early

\footnotetext{
${ }^{16}$ See, for example, the diversity revealed in Jeff Smith, "The Amish Use Tech Differently Than You Think. We Should Emulate Them," Washington Post, Feb. 17, 2020.
} 
years. Pulling teeth unnecessarily is a cruel and dangerous precedent in lieu of education in dental care, referrals to trained dentists, and options for care before the teeth have to be removed. ${ }^{17}$

The education departments of the state and local school systems should be sure that children are learning the scientific method and understanding the criteria by which beliefs are assessed. This might be anathema to Amish school boards, but discussions and basic information should be available to adults and children.

Medical committees and groups could do focus group training and develop systems of mobile van examinations that would bring medical care to the farms and villages where the Amish are located. The establishment of outlying clinics with ties to medical centers is a very good innovation that allows early and complete care close to home for many Amish families.

The recruitment and training of Amish medical personnel could start with the cadres of men who act as community nurses and caretakers. This could be expanded to women and all be given regular seminars on prevalent topics, such as dental hygiene, nutrition, wound care, and prenatal care.

Because of their conservative lifestyle, their communal life that provides oversight of behavior, and their willingness to help one another and provide personal care for those with health needs, it is easy to ignore ways to remedy some of the failures of the medical system in providing care for the Amish. Information carried to the CAM community through extra training and oversight would also be helpful. The basic good health of the Amish, who rarely smoke or drink and live an energetic life, offers many lessons to the English community. Our English and Amish communities are intertwined in historic and current functions and interactions. If we respect the ways in which we wish to live, provide a maximum of home-based care for those that want and need it, and increase health care education to all our rural populations so that we all are able to take an active role in informed health care decision-making, our shared communities will reap the health and social benefits.

\section{Bibliography}

Adams, Carolyn E., and Michael B. Leverland. "The Effects of Religious Beliefs on the Health Care Practices of the Amish.” The Nurse Practitioner 11, no. 3 (Mar. 1986): 58, 63, 67. https://doi.org/10.1097/00006205-198603000-00008

Cates, James A. Serving the Amish: A Cultural Guide for Professionals. Baltimore: Johns Hopkins University Press, 2014.

Crawford, Stephanie Y., Aimée M. Manuel, and Bruce O. Wood. "Pharmacists' Considerations When Serving Amish Patients." Journal of the American Pharmacists Association 49, no. 1 (Jan.-Feb. 2009): 86-97. https://doi.org/10.1331/JAPhA.2009.07160

de Jonge, Peter, Klaus J. Wardenaar, H. R. Hoenders, Sara Evans-Lacko, Viviane KovessMasfety, Sergio Aguilar-Gaxiola, Ali Al-Hamzawi, et al. "Complementary and Alternative

\footnotetext{
${ }^{17}$ Heima et al., "Oral Health and Medical Conditions."
} 
Medicine Contacts by Persons with Mental Disorders in 25 Countries: Results from the World Mental Health Surveys." Epidemiological and Psychiatric Sciences 27, no. 6 (Dec. 2018): 552-67. https://doi.org/10.1017/S2045796017000774

Flurry, Mitchell D., Kelsie L. Herring, Logan W. Carr, Randy M. Hauck, and John D. Potochny. "Salve and Burdock: A Safe, Effective Amish Remedy for Treatment of Traumatic Wounds?" Advances in Skin and Wound Care 30, no. 5 (May 2017): 213-17. https://doi.org/10.1097/01.ASW.0000515079.07160.e3

Heima, Masahiro, Marc-Allen Harrison, and Peter Milgrom. "Oral Health and Medical Conditions among Amish Children." Journal of Clinical and Experimental Dentistry 9, no. 3 (Mar. 2017): e338-43.

Hurst, Charles E., and David L. McConnell. An Amish Paradox: Diversity and Change in the World's Largest Amish Community. Baltimore: Johns Hopkins University Press, 2010.

Kraybill, Donald B., ed. The Amish and the State. 2nd ed. Baltimore: Johns Hopkins University Press, 2003.

Kraybill, Donald B., Karen M. Johnson-Weiner, and Steven M. Nolt. The Amish. Baltimore: Johns Hopkins University Press, 2013.

Kristoffersen, Agnete E., Ann Ragnhild Broderstad, Frauke Musial, and Trine Stub. "Prevalence, and Health- and Sociodemographic Associations for Visits to Traditional and Complementary Medical Providers in the Seventh Survey of the Tromsø Study." BMC Complementary and Alternative Medicine 19 (2019): 305. https://doi.org/10.1186/s12906-019-2707-1

Reiter, Paul L., Mira L. Katz, Amy K. Ferketich, Electra D. Paskett, Steven K. Clinton, and Clara D. Bloomfield. "Complementary and Alternative Medicine Use among Amish and Non-Amish Residents of Ohio Appalachia." Online Journal of Rural Nursing and Health Care 9, no. 2 (Fall 2009): 33-44. https://doi.org/10.14574/ojrnhc.v9i2.84

Rohr, Joseph M., Kristine L. Spears, Jenenne Geske, Birgit Khandalavala, and Mindy J. Lacey. "Utilization of Health Care Resources by the Amish of a Rural County in Nebraska." Journal of Community Health 44, no. 6 (Dec. 2019): 1090-97. https://doi.org/10.1007/s10900-019-00696-9 